\title{
Producing and Consuming the Painter Raphael's Birthplace
}

\author{
By Massimo Giovanardi (at that time, University of Urbino)
}

It is possible to contact the author at: m.giovanardi@le.ac.uk

This paper has been published as: Giovanardi, M. (2011). Producing and consuming the painter Raphael's birthplace. Journal of Place Management and Development, 4(1), 53-66.

Purpose - This article draws on Johnson's "Circle of Culture" to develop a cultural approach for studying place-marketing internal audience. My research project on the small Italian Renaissance city of Urbino explores how a number of marketing events dedicated to the painter Raphael, who was born there, have been produced and then received among different urban populations (dwellers, commuters, students etc.). The second part of the article conceptualizes events as both "inward" and "outward" forces and compares the Raphaellian Events with some of Urbino's traditional festivities.

Design/methods/approach - This is a qualitative study that applies discourse analysis to media texts, official documents and forty-two in-depth interviews held with both local officials and internal place consumers.

Findings - The inquiry reveals a predominance of discourses in support of the events: civic pride, identification, economic benefits. What is more striking is that some participants not only appreciated the marketing events but "went beyond" by producing discourses in support of a more intensive exploitation of Urbino's cultural and heritage resources.

Research limitations/implications - Quantitative research is recommended to generalize evidence stemming from my ethnographic inquiry and to measure "the magnitude" of the different discourses produced by the people.

Originality/value - This article contributes to overcoming the materialist perspective which underpins a consistent part of literature by showing a new (counter)example of the "nonoppositional voices" of place-marketing. Moreover, it sheds more light on how "tertiary communication" takes place and how it can be properly investigated.

Category of paper: Research paper

Key-words: place marketing, place branding, internal audience, heritage, personality branding, events. 


\section{Introduction}

It is rather unusual in place marketing literature to learn about people appreciating a marketing event that involved their city. It is even more unusual when people show themselves as willing to welcome other future strategic initiatives capable of valorizing urban cultural resources. This is the real "unconventional" situation described by this article in relation to Urbino, a small Italian Renaissance city and UNESCO Heritage Site lying on the Marche Appennines. Here several cultural marketing events were staged in 2009 to celebrate the painter Raphael, who was born in Urbino and is still one of the city's major symbols.

This article illustrates how I developed and applied a cultural framework in order to study the production and the reception of event-marketing representations among Urbino's community. This is a sort of "microcosm" whose social and economic life is strongly shaped by the presence of the University and of some valuable heritage amenities.

The last part of the article compares the Raphaellian Events with two of Urbino's annual festivities and discusses them in respect to a growing literature that understands urban events as an overlapping field between marketing and human sciences.

\section{Theoretical Background}

It is still ongoing the difficult but intriguing "translation" of marketing and branding from the realm of private firms into the one of places (i.e. Kavaratzis, 2004, 2010; Kavaratzis and Ashworth, 2005; Anholt, 2007). Particularly significant is the original framework developed by Kavaratzis (2004), who identifies the city image as the proper object of city marketing (ibid.: 62) and acknowledges three different levels of image communication: primary communication (the semiotic effect of the city's actions which are not mainly conceived as communication), secondary communication (the intentional and "traditional" communication) and tertiary communication (the word-of-mouth, consequence of the two controllable communication types, as well as a key element in the brand battlefield).

From a different perspective, urban branding and urban marketing techniques have been strongly criticized by sociologists and human geographers (cfr. Harvey, 1989; Philo and Kearns, 1993; Greenberg, 2000). The homogenization of cultural richness, the reductionist and controversial selection of 'what to show' and 'what to hide' and their 
exploitation as form of social control are the primary allegations (Colomb and Kalandides, 2010:176). This body of literature is usually underpinned by a materialist perspective and focuses on the "failure stories" of place branding, by highlighting the struggle between the monolithic representations framed by the marketers and the competing stories told by the "others".

Following Colombino (2009:280), however, we can identify a smaller body of literature focusing on the "non-oppositional voices" of place marketing. She cites some contributors (Brennan-Horley et al., 2007; Gibson and Davidson, 2004; Young et al., 2006) who pose challenges to the most widespread view that "place-marketing images are misrepresentations of locations that do not reflect how local residents think and feel about them" (ibid.: 280).

This article contributes to overcoming a materialist perspective which "prevents visitors or residents from being conceptualised as conscious, thinking and experiencing beings" (Selby, 2004:62) and to adopting a cultural approach which implies "a concern for context" (ibid.) and an awareness on how people actually encounter their city's marketed image. This means going beyond "the interpretations offered by the academics authoring the research" (Colombino, 2009:280) and discovering empirically how meanings are created and consumed.

\section{Framework and Methodology}

My inquiry embraces a cultural approach which draws on Johnson's "Circuit of Culture" (Johnson, 1987). Following recent suggestions (Selby, 2004; Gibson, 2005), it represents an effective tool to understand urban marketing events as transformation of meanings that are encoded and decoded over time by different social groups in different contexts.

In conceiving an event, producers ascribe to it certain meanings (moment of production); these take shape in specific textual representations that researchers can investigate through textual analysis (the moment of texts); as it is not possible to "infer the text-as-read from the text-as-produced" (Johnson, 1987:673), we must research empirically how the events are actually consumed and "read" by groups of place consumers (moment of readings); finally, the different subjective experiences of consumers influence the lived cultures - "the existing ensembles of cultural elements already active within particular social milieux" (ibid.:664) - which in turn mould the environment where new 
events will be produced.

It is by studying the Raphaellian Events through the lenses of this framework that we can discover how the internal audience has reproduced and/or contested the urban images forged - and the "story" told - by the promoters through the events. In order to do that, I drew on "interpretive methods" (Yanow, 2009:431) to analyze media texts, official documents and in-depth interviews held with 6 key organizers and 36 internal place consumers.

This latter group includes not only residents but also commuting workers and university students. The latter choice aimed to take into account the huge presence of students in the city (almost 15.000 registered in a total of 15.000 dwellers) and to acknowledge the increasing importance of new urban populations which live in cities without being residents (Martinotti, 1993).

I recruited this group of participants by a "snowball sample" process that started from my personal social-networks and sought to avoid the presence of likeminded people by using multiple initial contacts. People with low educational qualifications appear in the sample as well.

\section{Production}

Let us begin from the first moment of Johnson's circuit, by seeking to provide an insight into how the producers conceived the events: which meanings did they encode into them? By staging the "Raphaellian events" the city produces a Raphaelscape. This notion is adapted from Julier, who refers to "urban designscapes" as "the network of activities and artefacts that produce place-identity within cities" (Julier, 2005:869). Our symbolic environment, however, draws not on "the pervasive and multileveled use of the symbolic capital of design" (ibid.:874), but instead on art, and specifically on the painter Raphael's art.

We may argue that the 2009 events rather intensified an already working Raphaelscape. The artist has indeed always been a common trait of Urbino's everyday imagery production, as embedded in:

- The activities of the Raphael Academy (conferences, publications and celebrations about him);

- His birth-house which was also his father's bottega; 
- Two of his masterpieces displayed in the Duke's Palace;

- The names of local cultural institutions and businesses.

Within the actor-network underpinning the Raphaelscape we can distinguish protagonists and supporting actors. The two groups shared an agreement about Raphael's artistic, cultural and touristic value, but each one worked almost separately in a sort of "monadic governance".

The protagonists: enhancing cultural assets and boosting tourism

The main promoter of the initiative is the Superintendence of Cultural Heritage, a regional department funded by the national government. Led by its charismatic director, it worked in synergy with the Mayor for 4 years and outsourced to a private marketing company the task of marketing the event (sponsoring, promotion, logistics etc.). The meanings encoded by the Superintendence in the exhibition are mostly cultural and artistic. The event started as a research-project aimed at scientifically demonstrating that the painter's artistic training was deeply rooted in and influenced by his father's bottega and Urbino's cultural milieu. In the director's view, furthermore, the exhibition had to affirm that:

Urbino has to become an inevitable stage within an Italian tour on the Renaissance. Florence is not enough, Venice is not enough, Rome is not enough (interview with the director available on http://www.youtube.com/watch?v=GgTKjTqvav4; accessed September, 202010 )

"We work also in order to ensure that Urbino has a lively image" - said one of the director's assistants. "Urbino needs a strong shake up" and "[the Exhibition] was a perfect example of this in action". Involving the local population in the event is also considered important and a ticket discount system was created in order to steer participation.

In the Mayor's view, the discourses on the economic benefits appear to be more explicit, but remain interwoven with the cultural message of the project: remarking the artist's relationship with the place: 
"It's the first time that Urbino has maneged to do a real exhibition able to attract tourists from all over the world and at the same time to affirm that Raphael never departed from Urbino, which remained the centre of his interests" (Mayor's speech reported in Bernardini, 2009)

The supporting actors: compensating for the exhibition's limitations

The Regional Territorial Development Agency and the city's Culture and Tourism Department each staged a collateral review in order to fill the gaps of the Exhibition and make the cultural and touristic offer more engaging. They both criticize the Superintendence's tendency to use the event for itself and to not involve other stakeholders in the project.

The regional initiative "Around Raphael" was conceived in order to shed more light on key places of Raphael's life through a number of edutainment events. The idea was to go beyond science and "to promote the territory by communicating Raphael in a slightly more popular way and by showing him from different perspectives which the exhibition did not take into account" (interview with the project's director).

Similarly, "Utopia of Raphael" was a local review "addressing visitors and citizens" and "making people discover other Raphaellesque places, eat the food of that time, listen to the readings of that historical period" (interview with the Councillor). This review is also part of en event marketing strategy built around the brand "Urbino the World Capital of Utopia", created by the Councillor to present the city as "an ideal city, a utopian place, a constantly evolving space" (Mazzoli, 2008:68).

\section{The moment of the text}

Moving on to the second moment of Johnson's framework, we analyze here the specific textual forms that the producers' ideas took on in developing the happenings. Yet, the Raphaellian Events, taken together or separately, do not constitute a single text but instead an assemblage of two-dimensional (promotional material, website etc.), threedimensional (the ongoing events themselves and the characters involved) and nondimensional texts (radio commercials). What unifies them is that they all celebrate 
Raphael in relation to his birthplace, contributing to forge this "personality association" (Ashworth, 2010) in multiple ways. We analyze firstly the Exhibition and, in particular, the artifacts included in the event itinerary, the promotional material, the radio commercial and the official website.

\section{The Raphael Exhibition}

The main event portrayed the association between the city and the character following a common and traditional format: an art exhibition that got loans from many international museums. It juxtaposed pictures of earlier Raphael with the ones of his father and other painters working in the Duke's court in Urbino and aimed to demonstrate the artistic similarities. This is a re-appropriation of Raphael that is also witnessed by a huge quantity of documents illustrated in the exhibition's catalogue. The exhibition was promoted through a national and international promotional plan, whose tone and style appear rather traditional but anyway consistent with the producers' discourses.

It is possible, however, to notice a certain inconsistency between the producer's arguments about the importance of Urbino for understanding Raphael and how this idea was "translated" into the textual embodiment. The painter's birth-house, only 500 hundred metres on foot from the main venue, was clearly undervalued by the Exhibition, as it was not included in the main itinerary nor was its existence particularly stressed. This is paradoxical for a text designed to valorise the artist's local roots: the danger is to reinforce the perception that "this is a Raphael exhibition, not the Raphael Exhibition in his birth-city".

There are other clues indicating that the city was not presented as the "star" of the event. The radio commercial does not say something like "Raphael comes back to his birthplace", but it is mainly focused on the art event. This incomplete textual fusion between the exhibition and the city is mirrored also in the structure of the promotional brochure, which is divided into three parts: the first on the Exhibition, the second on Urbino's other cultural resources, the third on the region Le Marche.

Finally, let us consider the web-site and its apparently mysterious disappearance. For several months it functioned as the official online representation of the Raphaelscape and its url (http://www.raffaelloeurbino.it) was (and still is) mentioned as the main informational platform in all the printed and online news regarding the event. A couple of months after its end, however, by clicking on the url I got the response "page not found". 
What is worse is that a couple of months later by typing the same address I was redirected to the page http://www.visitflorence.com/florence-history-and-culture/raphael.html where I could read a presentation of Raphael's activity in Florence. As the domain was not renewed by the society working for the Superintendence, a Tuscan marketing agency bought it. As a consequence, not only the "raffaelloeurbino.it" stop publicizing that "Raphael belongs to Urbino", but also started conveying messages reinforcing the association with the "competitor" city, leading to a sort of boomerang effect.

\section{The Collateral Reviews}

We discuss now the textual shapes of the two collateral happenings by drawing on the analysis of their programmes' content, featured characters and of the promotional materials.

Part of the "Around Raphael" schedule seems actually to address a wider audience: it features as guests some TV characters, such as a famous actor performing readings about Raphael's life and figures who contributed to the popularization of science in Italy. Moreover, it draws on the theatre as an additional tool for entertaining people and the advertising poster is based on a fresh and eye-catching visual. However, the subjects of many conferences deal specifically with art and science and even the titles may seem of little allure to those who do not have an extensive cultural background (i.e. "Allegory of Raphael's Mathematics"). These elements are in contradiction to the producers' statements.

The local review offered people the possibility to follow artistic routes through the places of Raphael's youth, to order Renaissance food at restaurants and to visit a further exhibition by young artists of Urbino's Academy who have played on Raphael's masterpieces. This programme certainly thematises "Raphael and Urbino" in further interesting ways and enriches the imaginary production about Raphael and his intimate relationship with the city. However, some elements seem to contradict the producer's aim of improving the touristic offer: the artistic routes were limited only to seventy places each and were staged only at the weekends. The art critics leading them, moreover, were wellknown only to the local community and therefore unlikely to seduce a national audience.

Did people read into these texts what the organizers really meant? 


\section{The "moment of the context"}

Accepting Gibson's proposal (2005:272), I condense here two distinct moments of Johnson's Circuit: “the moment of reception, in which individual audience members receive the text and produce their own readings; and the moment of the lived cultures, that is when individual readings play back into the social relations that constitute everyday life". My analysis detected three textual communities, groups of people sharing the same understanding of the "text".

\section{The indifferent and superficial readers}

A first family of readers, mostly composed of students and commuters, can be referred to as "indifferent and superficial" as the Raphael Exhibition hardly captured their interest. Far from attaching negative meanings to the happening, they show respectively a scarce or tepid involvement in the matter and portray a vague picture of the city during the event.

The indifferent readers simply remember that an exhibition about Raphael "took place" and attracted "a great influx of people". Some students say they were too busy in those months while some non-resident workers reveal that they were just not interested. They did not visit the exhibition and did not notice the collateral events.

The superficial readers state that they appreciated the exhibition, but their judgments remain, as if to say, on the surface. They did not enjoy the artistic-scientific aspects, nor seem to express civic pride in relation to the celebration of such an urban icon like Raphael. The student Matteo explains he went to the exhibition out of "curiosity". Another student, Luigi, expresses his positive judgment in relation to the hundreds of visitors who made the city more lively, a fact that - as he tells me - "made me appreciate Urbino".

The satisfied/enthusiastic readers

A more fervid and convinced support for the events characterizes this second textual 
community. It comprises mostly residents who describe a clear appreciation of the exhibition (and in some cases of the collateral events, too), by showing a deeper involvement in and a greater awareness of the place's social and economic life. These individuals articulate their positive vision in three different ways, each one would define a sub-reading-community if it wasn't that they are sometimes juxtaposed in the same participant's answers.

In the cultural-symbolic reading people identify with the urban imagery stemming from the Raphaelscape. The celebration of the Renaissance artist is for them a reason for civic pride, like for Riccardo, a young guy living in a town not far from Urbino, who told me how much he liked the opportunity to see some of Raphael's pictures "here, where Raphael was born and lived for a part of his life". From a much wider perspective the resident Angelo describes his pride in relation to urban cultural policies which appear to have "finally" functioned correctly:

It was the first time after many years that I saw Urbino's name shining in the way that once made it famous!

Respondents performing the scientific-artistic reading seem to attribute huge importance to the scientific thesis underpinning the exhibition: Raphael was strongly influenced by Urbino's cultural and artistic environment. They understand the main event primarily as an art happening, an attitude that is clearly exemplified by Marilena's glowing account:

Maybe I grasped this: seeing already in the first Raphael a master. [...] The fact that he departed from Urbino... I always thought this fact might have given Raphael more chances to improve himself as a poet too; but seeing that exhibition I thought... that maybe I was wrong! [laughing] he would have been a master even if he stayed in Urbino!

Finally there are those who appreciate the exhibition mainly because of its notable economic impact. We are dealing here with the economic reading, which for example shapes the report rendered by Franco, a person involved in the coordination of a trade association. He contends that the memory of the exhibition is positive 
because it attracted a certain number of visitors and created a certain vibration within Urbino's scenario. It's one of the things that was urged among different stakeholders! [...] a positive experiment: it moved the city's economy!

\section{The strategist readers}

The majority of the respondents (14 of 36) can be labeled "strategists" and constitute the most interesting and unexpected textual community. They appear highly supportive of the events by developing the same three readings that distinguish the aforementioned family: cultural-symbolic, scientific-artistic and economic. However, it is worth stressing their peculiarity: besides appreciating the Raphael Exhibition and sometimes the collateral review, they go on further to explain how the events should have been improved to meet more appropriately the city's needs and how artistic resources should be managed by local authorities. The satisfaction for the prestigious happening couples in their discourses to the awareness that more efforts are required in order to fully exploit the city's potential in terms of cultural and heritage resources.

The following four points of criticism raised by the strategists reveal how much they are favourably disposed toward initiatives able to take advantage of the city's cultural assets.

A "sleeping city", which "sells itself short"

A first set of observations are raised against the general "biorhythm" of the city and the way the local government manages to control it. A place that, although put in bright light by Raphael Exhibition, is perceived as culturally and economically stagnant - as if it were "dozing" (interview with the resident Alvaro). While during the event "it was like the city was in a state of celebration”.

the only regret is that this has been an isolated case. They never do anything here, the city lends itself to such things. [...] It has been a renowned event.

Such a vision is shared also by those having lower educational qualifications, like the resident Aldo. He believes that 
Urbino lacks things like that. Things that should be done more often. Art is something to exploit much more here in Urbino. [...] Nothing happens here... it's like a Sicilian town... [speaking in dialect]

The same discourse is developed more eloquently by a resident shopkeeper, Liviana:

we all had this perception of a beautiful, enchanted city, that is how we'd like the city to always be [...] if we sometimes had such cultural events, we would have a different city [...]. The city, instead, always sells itself short [...]

If [...] you don't say that this is an international city, if you don't make it distinctive in some way, if you don't communicate it in a different way, this is a city which will remain like it is now $[\ldots]$

The involvement of the community could have been greater

A second discourse concerns the scarce involvement of the community in the organization and the fruition of the events. Regarding the first issue, two members of Raphael's Academy regretfully underline the missing involvement of their association in the staging of the exhibition. Furthermore, the student Francesco is disappointed by the University's passiveness, as it missed an opportunity to organize something relating to Raphael.

With regard to the obstacles to local fruition, the resident Sandro is proud of the city but laments about the fact that Urbino welcomed people "from Japan, from China" while “some people living in Urbino didn't even know of its existence”. The local government, accordingly, should have done something more. Valentina praises the event but regrets the ticket discounting system, which did not favour people's participation enough: "it would have been nice" in her view to give "citizens and students the possibility to visit it even two, three, four times". "It is little forward-thinking - argues Francesco again - not to allow students free access. Well, more or less there are 5.00o students living here: if they take friends and relatives there [to the exhibition]...". This tactical view therefore considers the students as the place's ambassadors, a key concept of place branding knowledge (Anholt, 2007:105). 


\section{Raphael is undervalued here}

Both students and residents admit that their city usually devotes little consideration to such a notable character. These are the student Sarah's feelings:

When I discovered these cultural events I remained so very impressed because... or better still, for me he should be exulted every year...

Her feelings are echoed by two dwellers. For the young girl Franca "maybe Urbino doesn't praise him like it should". Giovanna focuses on how "different it would be if Urbino had a permanent Raphael exhibition given the fact that Raphael was born here and Urbino is also a very important cultural city".

\section{Organizational weaknesses: the number of the pictures and the communication}

Some readers are more specific by noticing, for example, that "there could have been some more pictures" (interview with Alvaro). Besides acknowledging the event's success, the resident Maurizio points out that

the narrowness of the material displayed, I think, might have an impact on the numbers regarding the exhibition. Because, yes, it has been a success for Urbino but if we compare it with similar events in other cities...

Another object of criticism is the communication to the external audiences. The economic reading made by Cristiano, a dweller involved in another commercial trade, contains a mixture of satisfaction and regret: the exhibition "in a difficult year from the point of view of economy allowed flows and business volume to remain substantially unchanged" but "a very important chance has been partially wasted because of how and when communication was staged". Even the elderly resident Ubaldo remarks that "communication started a bit late". According to the student Sarah, "it should be capitalized on social networks".

What about the collateral reviews? According to the few respondents able to 
remember something (only 6 out of 36 and mostly dwellers), the community's engagement with them seemed to be very scarce. Recollections appear rather blurred and often the participants were not able to remember anything even by looking at the promotional material I showed them. If it is true that almost all the accounts on "Around Raphael" and "Utopia of Raphael" are positive, we must conclude that the collateral events were just "side-dishes" in the "symbolic meal" digested by Urbino's populations.

\section{Events between marketing and human sciences}

To better understand to which extent people's imagination was captured by the Exhibition, I tried to "set a benchmark" by asking questions about how they understand two of Urbino's annual happenings (The Kite Festival and The Duke's Festival), with the aim to discover how these three events address and are conceived for local and/or external audiences. At this point, I must provide the reader with further theoretical insights.

On one hand, events and festivals are certainly key elements of cities' placemarketing strategies (Getz, 1991). Management-inspired literature has focused on the importance of events for boosting economic performances and for implementing branding strategies (Olympic Games and other sport competitions, European Capital of Culture, Universal Expo,...). In this view, an event's efficacy is measured in terms of generated economic benefits and of external audience's satisfaction.

On the other hand, scholars in social sciences tend to focus on less tangible dimensions, paying attention to the profound social meaning and value of events. A prevalent assumption in this field is that festivals and traditional festivities are often instrumentally developed by place marketing (i.e. Greenwood, 1972) and in actual fact "city authorities seem to misunderstand the social value of festivals and construe them simply as vehicles of economic generation or as 'quick fix' solutions to city image problems" (Quinn, 2005:939).

However, there is some clear evidence about the fact that sometimes events serve the needs of both residents and tourists. They can "celebrate a sense of place through organizing inclusive activities" (Derret, 2003:57) being at the same time charming attractions for external audiences. That is why we need a more holistic research approach that is more sensible to the "embedding of events in contextual environments" (Quinn, 2009:493) and that can be developed "through dialogue and a cross fertilization of ideas" (ibidem) among researchers. 
Building upon recent suggestions in the literature (Quinn, 2005; 2009) I conceptualize events as potentially both inward forces, capable of "making community", and outward forces, being touristic attractions and enhancing place recognizability. Every event can thus be positioned along a continuum from "inward force" to "outward force", where the "ideal" situation is when the two aspects result perfectly balanced. The picture describes how I applied this framework to Urbino's events:

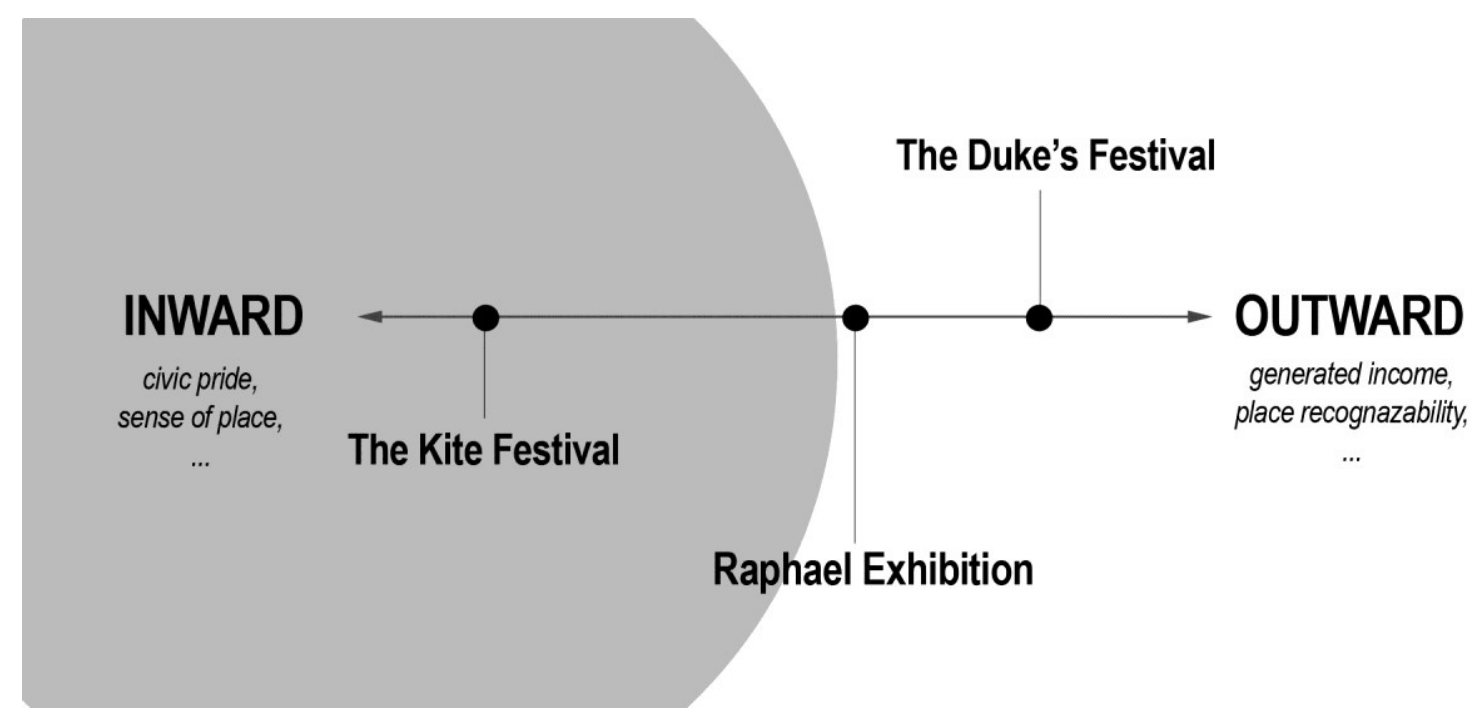

A limit to my inquiry is that I evaluated the outward force according to the local population's perceptions and to my direct observation, without considering quantitative data about the generated income of each event.

\section{The Kite Festival}

The Kite Festival is a traditional community-based happening which takes place every year in September. According to the words of residents and to my ethnographic observation, it is perceived as mainly an inward force.

Interviewees' faces usually lit up with joy after I asked my question about this event, like in the case of Alberto who exclaims:

It's wonderful! Have you ever seen that? [with amazement] You should come! [...] There are some really beautiful ones! They're not the best in the world maybe [...] but here there is no lack of wind! 
This festivity draws on a deeply rooted tradition. Massimiliano remarked that it "brings me back to when I was a child. I used to get there with the kite. We made it. Maybe it isn't easy to understand for someone who comes from outside ...”. It is, moreover, a tradition shared with other familiars: Marilena for example told me she usually makes the kite together with her husband and their two children.

During the event passion and care characterized the competing kite flyers and their supporters, and the moment of free flying the kites actively involved dozens of Urbinati with their children. As it has been observed in relation to this kind of festivities [Quinn, $2005 ; . .$.$] , during this weekend people are both producers (they make the kites, dress the$ colours of their respective districts etc.) and spectators.

However, differently from the Raphael's Exhibition, this Festival seems to be fully enjoyed only by the resident population, with the students being less involved (in the event). A practical issue is that the performance takes place on the first weekend of September, when the University has not yet completely restarted and, like the interviewed students explain, only a few of them have already resettled in Urbino. Celebrations, therefore, can be inclusive processes in respect to one social group but not for another.

Little space is provided for the tourists, too. The "kite ability competition" that I observed was followed just by a couple of foreigners and no seating arrangements were made available by the organizers in the venue. Furthermore there were no touristic signs and the kite "battle field" was therefore difficult to reach. Residents too seem to be aware that the Festival is not much about tourism.

\section{The Duke's Festival}

Only a few among the interviewees seem to appreciate "The Duke's Festival", a threeday medieval-style celebration which takes place every year in mid August. The predominance of discourses mobilized by the residents are against the "artificiality" of the celebration. According to Liviana "it's something just stuck on, something which has nothing to do with Urbino". Even though some participants point out that recently "it's been improving", the event is meaningful only to a part of the resident population.

On the other hand, the happening is seen as being designed to engage mainly the external audiences. According to Alvaro, "the Duke's Festival is perceived as being much loved only by those who come from outside. The Urbino dweller doesn't participate. [...] Those from the neighbouring towns come to the festival". Aldo goes straight to the point: 
"it is the festival that I go away from Urbino. It's the festival of the tourists..." [1]. This perception is mirrored in reality: differently from the Kite's Festival, the venues in which the parades and the ancient games take place allow tourists to follow them comfortably.

\section{The Raphael Exhibition}

While the Kite Festival is primarily an inward force and the Duke's Festival an outward force, the Raphael Exhibition can be considered as a good balance between the two. The community's involvement could have been greater and that is why I represented this event just a bit outside the grey area.

\section{Conclusion}

The staging of the Raphaellian Events can be seen as an example of "personality association" (Ashworth, 2010) in which the link between a city and an "artistic figure" was firstly scientifically demonstrated and then represented through cultural and tourist happenings. Now, let us focus on what really makes Urbino an original contribution to the literature.

It has already been widely acknowledged in the little literature available on the "nonoppositional voices of place marketing" (Colombino, 2009) how complex the relationship is between residents and the marketed image and how opposition is not the norm, as far as we observe groups of citizens supporting and reproducing place marketers' representations (Young et al., 2006; Colombino, 2009). Moreover, other studies included by Colombino under this categorization tried to evaluate, using also quantitative methods, the extent to which some place marketing events are welcomed by their internal audience (BrennanHorley et al., 2007; Gibson and Davidson, 2004).

While the satisfied/enthusiastic readers may correspond to some of the place consumers' groups highlighted in the existing research, the presence of the strategist readers demonstrates an unprecedented situation: these citizens (and city users) not only appreciated the marketing events built upon Raphael but "went beyond" by producing discourses in support of a more intensive exploitation of Urbino's cultural and heritage resources. Further events should be organized, other local resources should be valorized and communicated in ways which the entire city will capitalize on. By showing a sharp 
awareness of their "territorial capital" (Dematteis, 2005), these place consumers express a more "marketing-oriented" attitude than the local government itself.

Another significant contribution of the present study lies in its effort to comprehend a marketing event's importance for local place consumers by "benchmarking" it with their understanding of other place-making events, which are positioned along a continuum from inward-oriented to outward-oriented.

Finally, this piece of research could be inspiring also for place branding scholars, since it paves the way for reaching a better understanding of how "tertiary communication" (Kavaratzis, 2004:69) actually functions in places (various interpretive communities each performing its own reading of the same communicative action) and how it should be investigated (drawing on Johnson's circuit of culture). Indeed, the role of local communities in guaranteeing the success of place branding is one of the main conceptual areas which will underpin the future development of the discipline, as recently noted by Ashworth and Kavaratzis (2010:237).

I would like to conclude with a question. As it is from medium and small places that the most part of case-studies about the non-oppositional voices come from (Colombino, 2009; Brennan-Horley et al., 2007; Gibson and Davidson, 2004; Derret, 2003 as well as my research-project on Urbino), maybe time has come to tackle more seriously the problem of scale. How do place dimensions shape the production and the consumption of the marketed image? This is one of the many unbeaten tracks that further research is called to explore.

[1] This is a literal translation from the original but incorrect Italian.

\section{References}

Anholt, S. (2007), Competitive Identity: The New Brand Management for Nations, Cities and Regions, Palgrave Macmillan, Hampshire, UK.

Ashworth, G. (2010), "Personality association as an instrument of place branding: possibilities and pitfalls", in Ashworth, G. and Kavaratzis, M. (eds.), Towards Effective Place Brand Management, Edward Elgar, Chattenham, UK, pp. 222-233.

Ashworth, G. and Karavatzis, M. (2010), "Conclusion: in search of effective place brand 
management”, in Ashworth, G. and Kavaratzis, M. (eds.), Towards Effective Place Brand Management, Edward Elgar, Chattenham, UK, pp. 234-238.

Bernardini, M. (2009), "Raffaello a Urbino fa rinascere la città", Il Messaggero, 4 April, p. 49.

Brennan-Horley, C., Connell, J. and Gibson, C. (2007), "The Parkes Elvis revival festival: economic development and contested place identities in rural Australia”, Geographical Research, Vol. 45 No.1, pp. 71-84.

Colomb, C. and Kalandides, A. (2010), “The ‘be Berlin' campaign: old wines in new bottles or innovative form of participatory branding?”, in Ashworth, G. and Kavaratzis, M. (eds.), Towards Effective Place Brand Management, Edward Elgar, Chattenham, UK, pp. 173190.

Colombino, A. (2009), "Multiculturalism and time in Trieste: place-marketing images and residents' perceptions of a multicultural city”, Social \& Cultural Geography, Vol 10 No. 3, pp. 279- 297.

Dematteis, G. (2005) "I modelli di sviluppo e le dinamiche del 'locale'”, paper presented at the conference "Modelli di sviluppo locale", 22 September, Region Lombardia, Milan, available at:

www.irer.it/pisl/pisl/prodotti/convegnieseminari/convegno 22sett2005/folder.2006-0104.4980126616/ (accessed 14 November, 2010)

Derrett, R. (2003), "Making sense of how festivals demonstrate a community's sense of Place”, Event Management, Vol. 8, No. 1, pp. 49-58.

Getz, D. (1991), Festival, Special Events and Tourism, van Nostrand Reinhold, New York. Gibson, C. and Davidson, D. (2004), “Tamworth, Australia's 'country music capital': place marketing, rurality, and resident reactions", Journal of Rural Studies, Vol. 20, pp. 387404 .

Gibson, T. A. (2005), "Selling city living: urban branding campaigns, class power and the 
civic good”, International Journal of Cultural Studies, Vol 8, No. 3, pp. 259-280.

Greenberg, M. (2000), "Branding Cities: A Social History of the Urban Lifestyle Magazine", Urban Affairs Review, Vol. 36 No. 2, pp. 228-262.

Greenwood, D. (1972). "Tourism as an Agent of Change: A Spanish Basque Case Study", Ethnology, Vol. 11, No. 1, pp. 80-91.

Harvey D. (1989), "From Managerialism to Entrepreneurialism - the Transformation in Urban Governance in Late Capitalism”, Geografiska Annaler Series B-Human Geography, Vol. 71 No. 1, pp. 3-17.

Johnson, R. (1987), "What Is Cultural Studies, Anyway?", Social Text, Vol. 6 No. 1, pp. 388o, now in Gray, A., Campbell, J., Erickson, M., Hanson, S and Helen, W. (Eds.) CCCS selected working papers, Vol. 1, Routledge, NewYork, 2007, pp. 655-693.

Johnson, R. (1986) 'The Story So Far and Further Transofmations?' in Punter, D. (Ed.), Introduction to Contemporary Cultural Studies, Longman, London, pp. 277-313.

Julier, G. (2005), "Urban Designscapes and the Production of Aesthetic Consent", Urban Studies, Vol. 42, No. 4/5, pp. 869-887.

Kavaratzis, M. (2004), "From City Marketing to City Branding: Towards a Theoretical Framework for Developing City Brands", Place Branding and Public Diplomacy, Vol. 1 No. 1, pp. 58-73.

Kavaratzis, M. (2010), "Is corporate branding relevant to places?", in Ashworth, G. and Kavaratzis, M. (eds.), Towards Effective Place Brand Management, Edward Elgar, Chattenham, UK, pp. 36-48.

Karavatzis, M. and Ashworth, G. J. (2005), "City Branding: an effective assertion of identity or a transitory marketing trick?", Tijdschrift voor Economische en Sociale Geografie, Vol. 96, No. 5, pp. 506-514.

Martinotti, G. (1993), Metropoli: la nuova morfologia sociale della città, Il Mulino, 


\section{Bologna, I.}

Mazzoli, L. (2008), “La Capitale Mondiale dell'Utopia: libri e giochi per una città senza tempo", Siti, Vol. 4, No. 4, pp. 68-71.

Philo, C. and Kearns, G. (1993), "Culture, history, capital: a critical introduction to the selling of places”, in Kearns, G. and Philo, C. (eds.), Selling Places. The City as Cultural Capital. Past and Present, Pergamon, Oxford, pp. 1-32.

Quinn, B. (2005), “Arts festivals and the city”, Urban Studies, Vol. 42, No. 5/6, pp. 927944 .

Quinn, B. (2009), "Festivals, events and tourism”, in Jamal, T. and Robinson, M. (Eds), The SAGE Handbook of Tourism Studies. Sage, London, pp. 483-503.

Selby, M. (2004), Understanding Urban Tourism: Image, Culture and Experience, I.B. Tauris, London.

Yanow, D. (2009), "Interpretive Ways of Knowing in the Study of Politics”, in Pickel, S., Pickel, G., Lauth, H.J. and Jahn, D. (Eds.) Methoden der vergleichenden Politik- und Sozialwissenschaft: Neue Entwicklungen und Anwendungen, VS Verlag fuer Sozialwissenschaften, Wiesbaden, pp. 429-439.

Young, C., Diep, M. and Drabble, S. (2006), "Living with difference? The 'cosmopolitan city' and urban reimaging in Manchester, UK”, Urban Studies, Vol. 43 No. 10, pp. 16871714 . 